\title{
Estimation of Kinetic Parameters During the Treatment of Steelmaking Slag Expansibility Data
}

\author{
Tamires Cristina Costa ${ }^{*}$, Alex Vazzoler ${ }^{a}$, Wilton Pacheco de Araújo ${ }^{a}$, Edelize Angélica Gomes ${ }^{a}$ \\ ${ }^{a}$ Engenharia Química, Centro Universitário do Leste de Minas Gerais, Avenida Tancredo Neves, 3500 , \\ Universitário, Cel. Fabriciano, MG, Brazil
}

Received: July 19, 2017; Revised: November 01, 2017; Accepted: November 10, 2017

\begin{abstract}
Steelmaking slag (SS) is one of the largest generation waste in the integrated and semi-integrated plants, but it has application restrictions due to its high expansibility. To overcome these constraints, this research had as its main objective the reactions is kinetics parameters estimation that result in the expansion of SS using the Arrhenius global equation. It was obtained $12.5 \mathrm{~kJ} / \mathrm{mol}$ for activation energy and $260.42 \%$ for the pre-exponential factor. It was also noted that the temperature significantly impacts the final expansion values, increasing them exponentially. Furthermore the time of expansion of the slag obey an asymptotic equation $\left(\operatorname{Exp}=a-b . c^{t}\right)$ whose results presented initially having a large expansion velocity, which tends to zero at times very long when the material has stabilized.
\end{abstract}

Keywords: Steelmaking slag, activation energy, Arrhenius, expandability slag.

\section{Introduction}

The slags are synthetic rocks resulting from inclusions and non-metallic additions in steelmaking processes to promote the congregation of undesirable elements ${ }^{1}$.

According to Costa et al. $^{2}$ during the steel's manufacture the slag is the largest generation waste. They are constituted mainly of oxides of calcium $(\mathrm{CaO})$, magnesium $(\mathrm{MgO})$, silicon $\left(\mathrm{SiO}_{2}\right)$, aluminum $\left(\mathrm{Al}_{2} \mathrm{O}_{3}\right)$ and in smaller quantities of iron $(\mathrm{FeO})$, manganese $(\mathrm{MnO})$, also containing other elements such as sulfur ${ }^{3,4}$.

The proportion of the oxides used in the manufacturing process varies according to the chemical composition of the raw material, the type of process and the type of steel ${ }^{5}$. According to its specifications, it is possible to cite two main types of slag generated by steel mills: blast furnace slag (resulting from ore reduction) and slag from steel mill (Steelmaking Slag - SS - resulting from the refining process). Both slags are generated from distinct processes and, therefore, have different applications. Blast furnace slag is used mainly as an aggregate in the manufacture of cement, bricks and ceramics ${ }^{6,7}$. Nonetheless, SS has uses in paving, soil correctives and cement manufacture due to some of the main components, such as calcium and magnesium oxides, metallic iron, silicates, as well as several others. Other compounds in smaller quantities undergo chemical transformations in the presence of moisture and cause their volumetric expansion ${ }^{6,8-11}$.

Due to its expansive nature and the lack of technical criteria to determine its stabilization, as well as its use without the correct evaluation of the expandability ${ }^{2,12}$, SS has obtained performance problems like cracks in the asphalt layer, which contribute to the increase of discrimination

*e-mail: tamirescosta.eq@hotmail.com and mistrust in its use in road paving ${ }^{13}$. Consequently, for a better market is acceptance it is of the utmost importance to define a period of volumetric stabilization, called aged slag curing, is required, which varies according to temperature and humidity.

To express the expansion capacity, the time and temperature of the test are extremely important factors in the most applied methods. In Brazil, one of the methods that can be used is the DNIT ME $113 / 09^{14}$ test. This test was adapted by the Department of Transportation of the state of Minas Gerais (DER/MG) of the expansion test PTM 130/78 ${ }^{15}$, of the Department of Transportation of Pennsylvania, USA, and adopted in this research.

According to this test, with the time and the test temperatures for a slag with pre-established particle size and humidity, a model can be obtained to estimate its maximum expansion in a short period of time, without waiting years in a practical test.

The work's scope is characterize physically, chemically and microstructurally the SS to estimate the global kinetic parameters of the reactions that result in the expansion of the SS using the Arrhenius equation and to obtain a mathematical model/expression that estimates the expansion of the slag as a function of time.

\section{Experimental}

The SS used in this study was generated by a steel industry in the state of São Paulo/Brazil. The material was prepared, characterized and submitted to the expansion test by the method adapted from DNIT 113/2009 ${ }^{14}$, according to the following experimental procedure. All assays were performed in triplicate. 


\subsection{Material preparation}

After the SS had undergone a metallic recovery, crushing and sieving to obtain granulometry in the range of 0 to 19 $\mathrm{mm}$, approximately $50 \mathrm{~kg}$ of the slag yard was collected. This sample will be referenced as lot 01 . As the quantity of lot 01 was very large, a representative part of that quantity was prepared, by reduced sample, subjecting it to the characterizations presented in Figure 1, as well as the test of expandability, according to the standard adopted in this work.

The sample from lot 01 was ground in a Retsch/Germany ring vibrating mill, model RS200, suitable for efficient grinding of medium hardness materials. For the chemical and physical characterization, part of the sample was submitted to the new milling, to increase its reaction area. After milling, the sample was penciled in a No. 200 sieve (Tyler series) to ensure particle size less than $0.075 \mathrm{~mm}$ and subjected to the tests. The passing fraction in the No. 200 sieve $(0.075 \mathrm{~mm})$, during this work, will be mentioned as lot 02 .

The separate sample for the evaluation of the expansion was initially sieved and quarteted, taking advantage of the passing fraction in the No. $32(0.500 \mathrm{~mm})$ sieve and retained in the No. $150(0.105 \mathrm{~mm})$ sieve (Tyler Series). This fraction in the course of this work will be mentioned as lot 03 .

\subsection{Material characterization}

The actual density of the SS was measured by the Quantachrome Instruments automatic helium pycnometer model Ultrapyc 1200 e after removing any residual water from the sample. The nitrogen's fission, using BET isotherm (NOVA 1200e, Quantachrome Instruments), and the air permeability specific surface estimation through Blaine's method (PC Blaine Star, ZEB), were used to determine the specific surface area. Thermal analysis of the material was performed using thermogravimetric (TGA) and derivative thermogravimetric (DTA) techniques. The equipment used was the Netzsch STA 449 F3 Jupiter thermobalance, under argon atmosphere and synthetic air, with flow rate of 100 $\mathrm{cm}^{3} \mathrm{~min}^{-1}$, the heating rate of $283 \mathrm{~K} \mathrm{~min}^{-1}$ of temperature, for argon from 323 to $1173 \mathrm{~K}$ and for synthetic air from 473 to $1523 \mathrm{~K}$, with a mass spectrometer as detector of the gases released in the reactions.

To analyze the free lime content $(\mathrm{CaO})$, the ethylene glycol method was used, according to NBR $7227^{16}$, by neutralization titrations. Quantitative and semi-quantitative $\mathrm{X}$-ray fluorescence analyzes were performed using a WXRF S8 Tiger Spectrometer (Bruker). The X-ray diffraction model D8 Advance (Bruker) was used to determine the crystalline phases present in the SS structure.

The sample of lot 03 was embedded in cold curing acrylic resin, sanded (metallographic sieves with granulometry of 320,600, 800 and 1200 mesh) and polished (liquid alumina and in aqueous medium), for microstructural analysis. An M1m (Zeiss) Imager optical microscope, equipped for increases of 50,100, 200, 500 and 1000 times, and a digital camera for image capture were used. The digital processing of the images was done through AxioVision 4.8 software.

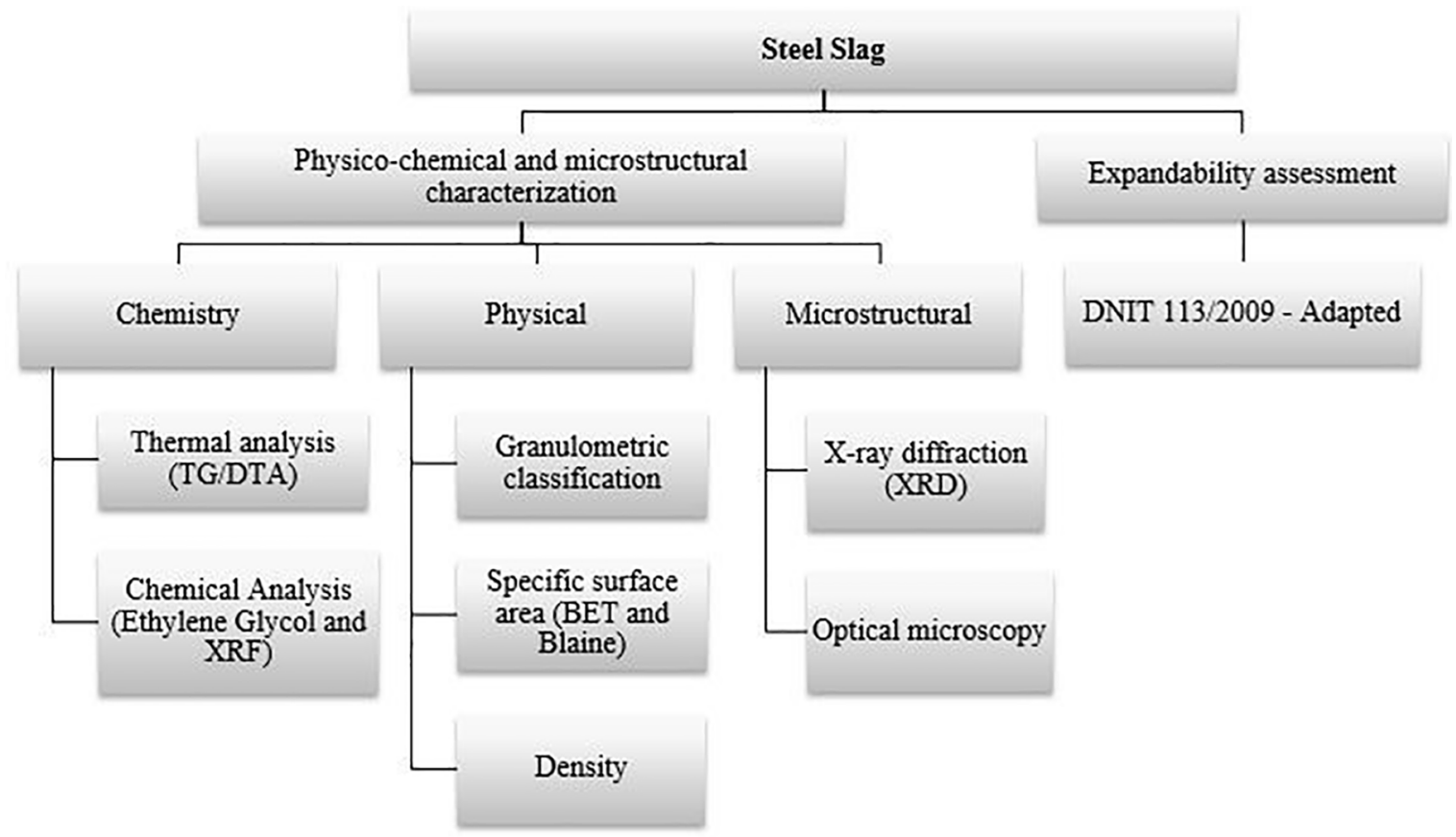

Figure 1. Experimental development flowchart 

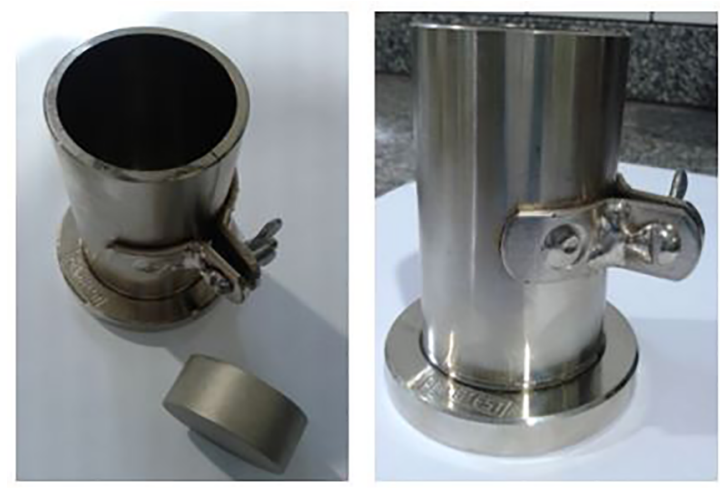

Figure 2. Mini-proctor tailored for expansion analysis

\subsection{Kinetics}

\subsubsection{Expansion evaluation}

The test method adopted in this research followed the experimental procedure of the norm of DNIT 113/2009 $\mathrm{ME}^{14}$, varying only the temperature of the test between 324 and $364 \mathrm{~K}$ to determine the kinetic constants and to develop a representative mathematical model for the expansion.

This method consists in the immersion of cylindrical specimens (Figure 2) compacted in the normal Proctor energy in a thermal bath with water at a given temperature for a period of 7 days being made daily readings of the volumetric variation as a function of the increase of height of the body of proof. Then, the specimens are removed from the thermal bath and taken to an electric oven at the same temperature. The test method establishes that the specimen must be kept in the condition of "saturation" (not submerged) for another seven days, with the daily readings of the expansion being carried out for an equal period.

The percentage of total volumetric expansion is that obtained after 14 days and is set at 3\% for cumulative expansion at the end of the test. To calculate it, equation 1 is used.

$$
\% \operatorname{Exp}=\frac{\left(L_{f}-L_{i}\right)}{L_{o}} * 100
$$

Whose variables, $L_{i}$ e $L_{f}$ are the mean of the initial and final readings respectively and $\mathrm{L}_{0}$ is the initial height of the sample, in millimeters. The expansion daily percentage calculation is obtained by dividing the difference between the daily readings performed and the initial measures of the each test piece.

\subsubsection{Data processing and estimation of kinetic parameters of expansion}

In order to obtain a mathematical representation of the data acquired during the expansion, used the programs Mathcad 6.0 and Origin (C) 7.5 SR4 for the reducing the errors and obtaining a mathematical model.
The kinetic scheme parameters determination used the Arrhenius empirical model. After expandability evaluation, the maximum expansion of each temperature within the same time interval was considered.

Now that it is possible to estimate kinetic scheme activation energy along with the pre-exponential factor through a linear regression of the experimental data. By applying the logarithm in the Arrhenius equation 2 we obtain a line, by the graph of $\ln (\mathrm{k})$ versus $\frac{1}{T}$, whose angular coefficient is $\frac{E_{n}}{R}$ and linear is $\mathrm{k}_{0}$.

$$
k=k_{0} \cdot e-{ }^{E a} /{ }_{R T}
$$

\section{Results and Discussions}

\subsection{Physical description}

\subsubsection{Density}

The density for the fraction corresponding to lot 03 was $3.27 \mathrm{~g} \mathrm{~cm}^{-3}$. It is observed that the SS has a real specific gravity close to the natural aggregates that vary from 2.0 to $3.0 \mathrm{~g} \mathrm{~cm}^{-317}$.

The determined result is consistent with the results found by Maruthachalam and Palanisamy ${ }^{18}$, Machado ${ }^{10}$ and Rohde ${ }^{19}$, ranging from 3.35 to $3.51 \mathrm{~g} \mathrm{~cm}^{-3}$. Both authors allege that the high value found for this material is a consequence of the high metallic iron content present in its composition.

\subsubsection{Specific surface area}

To evaluate the surface area of the sample, two different methods were used. The BET method yielded $5.56 \mathrm{~m}^{2} \mathrm{~g}^{-1}$ and the Blaine method, $0.1593 \mathrm{~m}^{2} \mathrm{~g}^{-1}$. According to Garcia ${ }^{20}$, these results show that lot 03 is composed of fine materials, which is one of the factors governing the rate of hydration reaction.

In addition, there is a large difference in the values determined for the SS surface area. This observed difference is due to the way the specific surface area is determined. The BET technique tends to provide a higher value in comparison to the Blaine technique, since the condensed nitrogen molecules adsorb in the pores and micropores of the particles, that is, the given value is the specific surface area $^{21}$, already in Blaine the value provided is from the accessible area for reaction.

\subsection{Chemical characterization}

\subsubsection{Thermal analysis (TGA/DTA)}

Thermogravimetric analysis (TGA) and its derivative (DTA) were used as an auxiliary technique to identify and quantify the compounds present in the sample of lot 02 . The strategy is to generate complementary and some redundant information to check the chemical composition of the sample. 
TG $1 \%$

DTG $/(\% / \mathrm{min})$

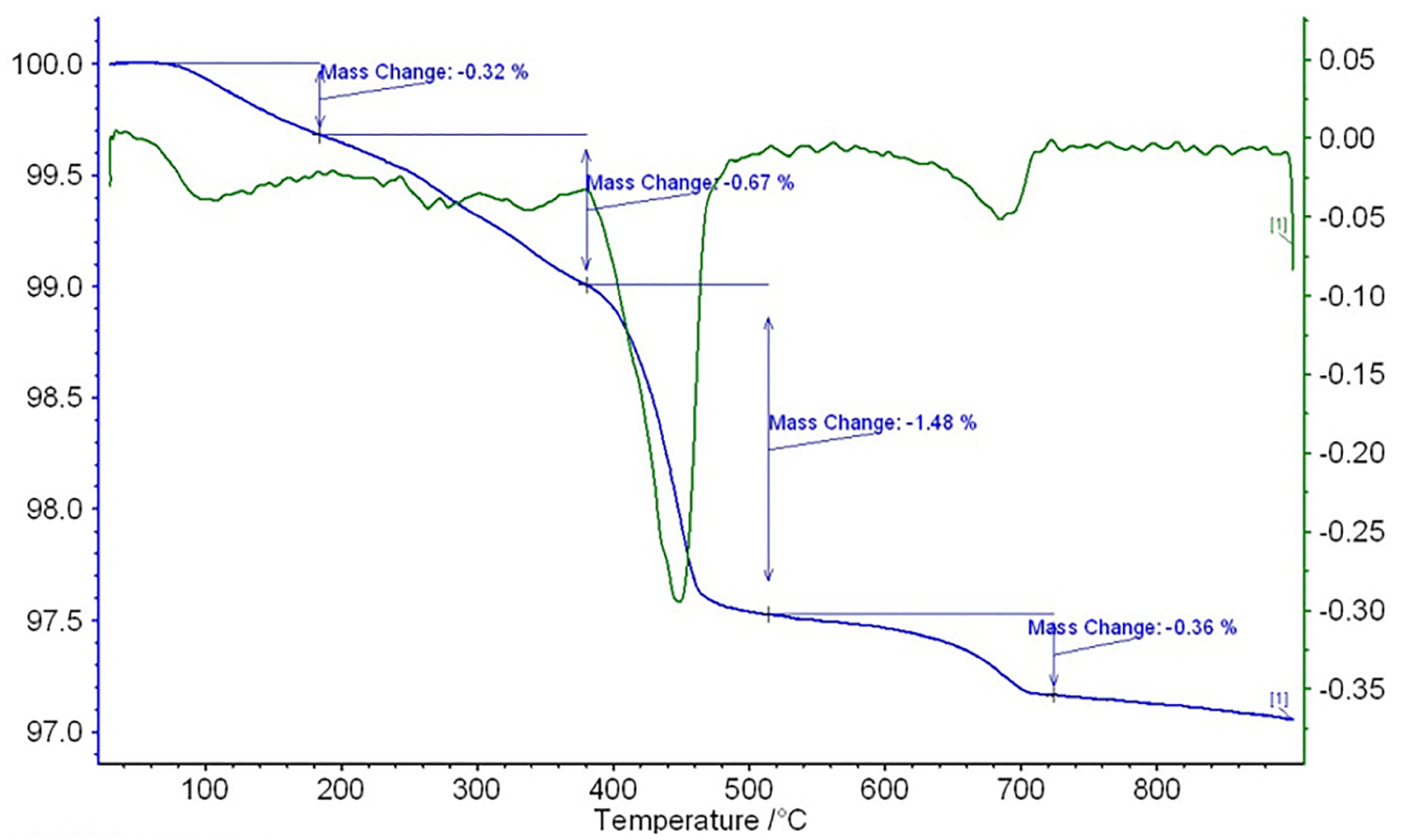

Figure 3. Thermal analysis in argon atmosphere

\section{TG $1 \%$}

DTG $/(\% / m i n)$

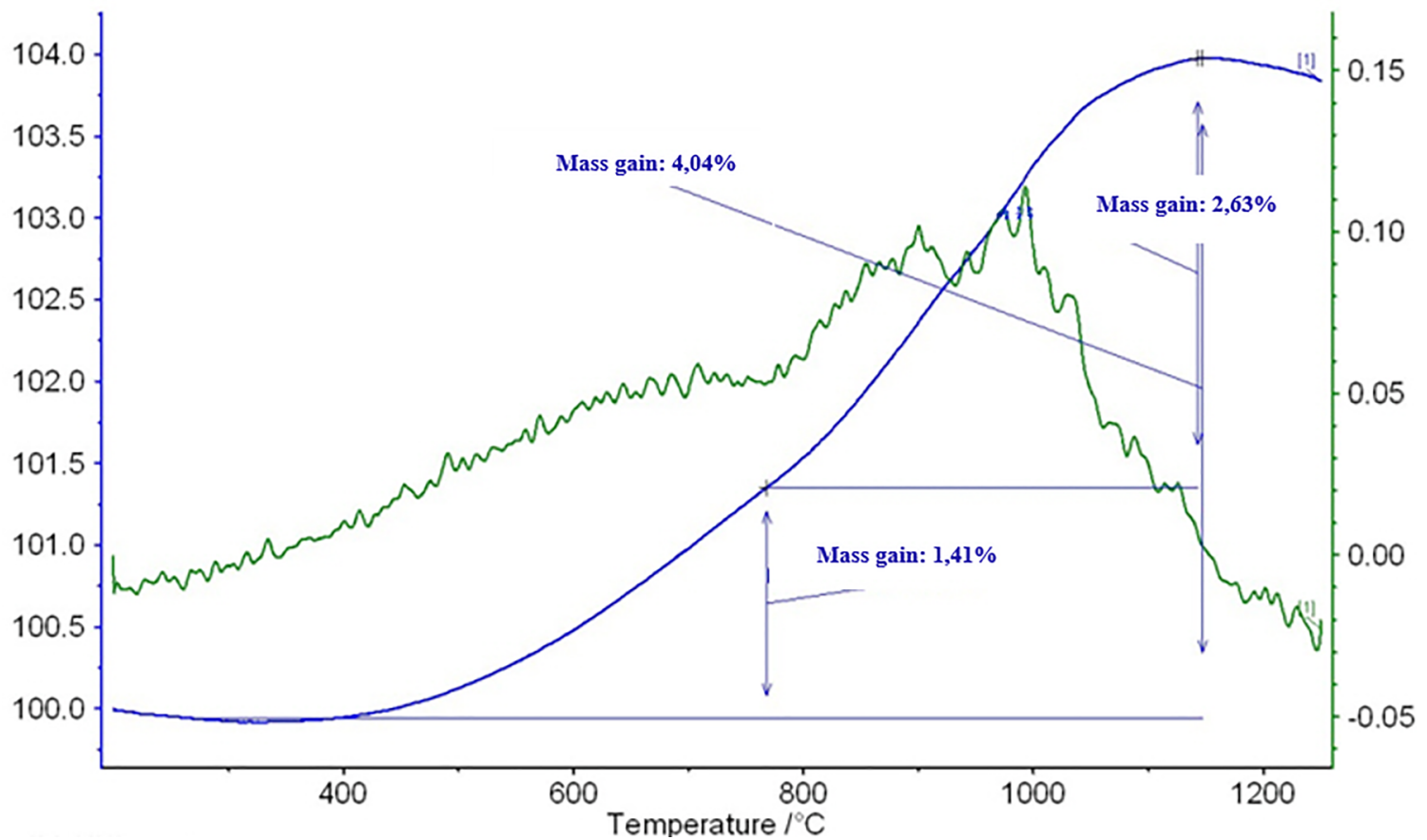

Figure 4. Thermal analysis in synthetic air atmosphere 


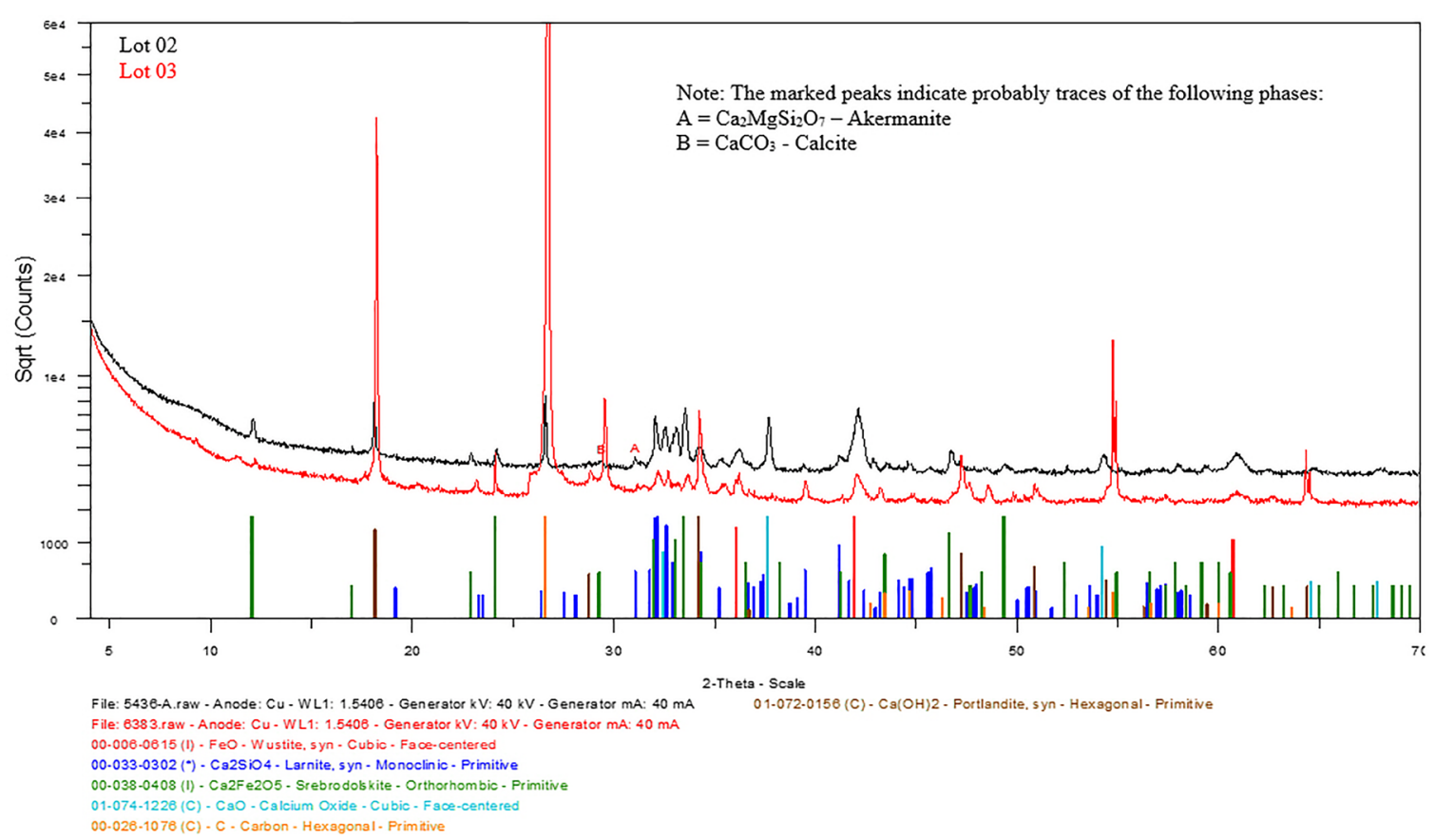

Figure 5. X-ray diffraction overlapping lot 02 and lot 03
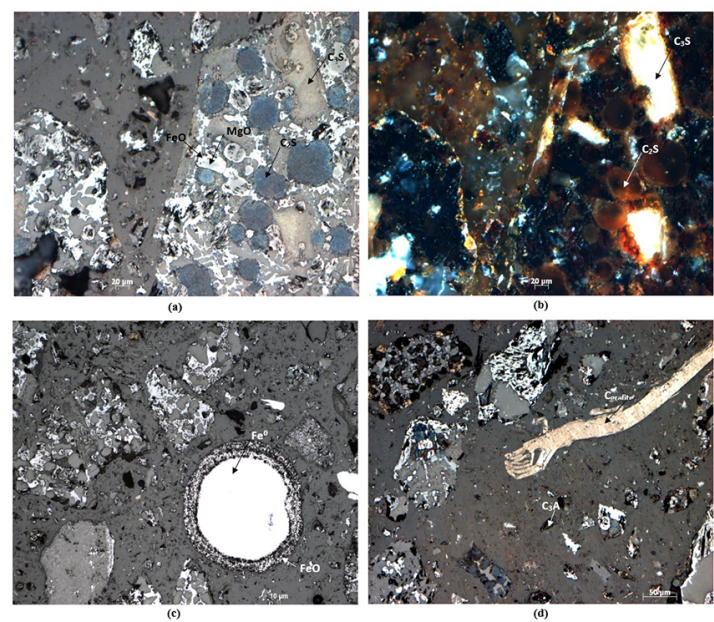

Figure 6. Photomicrography sample lot 03

Table 1. X-ray Fluorescence result.

\begin{tabular}{lcc}
\hline Elements & & $\%$ \\
\hline Total iron & $\mathrm{Fe}_{\mathrm{t}}$ & 21.94 \\
Wüstita equivalent & $\mathrm{FeO}_{\text {eq }}$ & 28.32 \\
Calcium oxide & $\mathrm{CaO}$ & 29.24 \\
Silicon dioxide & $\mathrm{SiO}_{2}$ & 7.27 \\
Magnesium oxide & $\mathrm{MgO}$ & 6.28 \\
Manganese oxide & $\mathrm{MnO}$ & 3.06 \\
Aluminum Oxide & $\mathrm{Al}_{2} \mathrm{O}_{3}$ & 1.97 \\
Phosphoric anhydride & $\mathrm{P}_{2} \mathrm{O}_{5}$ & 1.05 \\
Sulfur & $\mathrm{S}$ & 0.10 \\
Carbon & $\mathrm{C}$ & 0.50 \\
Titanium oxide & $\mathrm{TiO}_{2}$ & 0.27 \\
\hline
\end{tabular}

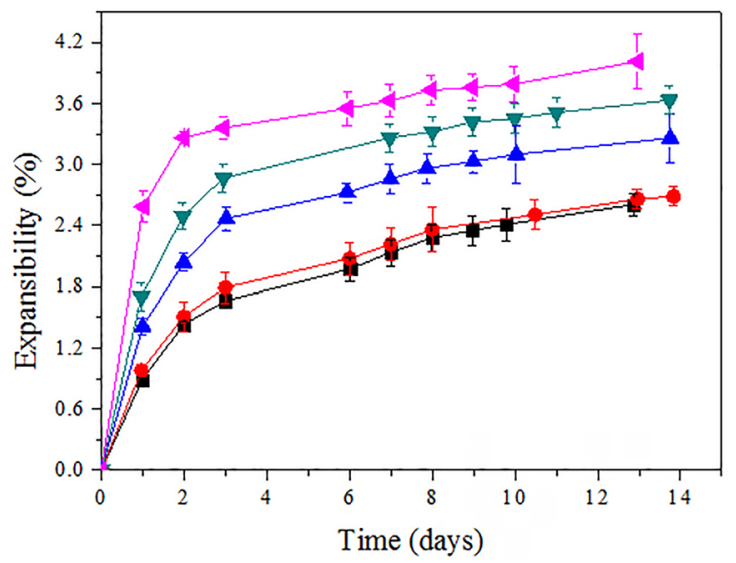

Figure 7. Average expansion (\% of initial length) determined by DNIT 113/2009 adapted method. - $324 \mathrm{~K}$; • $334 \mathrm{~K}$; $\boldsymbol{\Delta}$ - 344 $\mathrm{K} ; \boldsymbol{\nabla}-354 \mathrm{~K} ;<-364 \mathrm{~K}$

Figure 3 shows the thermogram of the sample of batch 02 performed under inert atmosphere (argon), slag mass loss in a function of temperature (TGA) and its derivative (DTA), which represents the rate of loss of pasta. The DTA curve allows identifying with more clarity peaks correlated with the dehydration and decarbonation phenomena of the present compounds. The most intense peak occurs near $723 \mathrm{~K}$ and refers to the decomposition of calcium hydroxide $-\mathrm{Ca}(\mathrm{OH})_{2}$ releasing water. It is observed that this peak has a small shoulder at a lower temperature, $701 \mathrm{~K}$, which possibly must be correlated to the decomposition of magnesium hydroxide $-\mathrm{Mg}(\mathrm{OH})_{2}$. Due to the small amount presented in the thermogram, this compound was not detected in the X-ray diffraction analyzes. 
Table 2. Data for estimation of kinetic parameters

\begin{tabular}{lccccc}
\hline $\begin{array}{l}\text { Expected } \\
\text { temperature(K) }\end{array}$ & $\begin{array}{c}\text { Measured } \\
\text { temperature (K) }\end{array}$ & Expansion (\%) & Time (days) & $\ln (\mathrm{k})$ & $1 / \mathrm{T}\left(\mathrm{K}^{-1}\right)$ \\
\hline 324 & 323.80 & 2.60 & 12.80 & 0.956 & 0.0031 \\
334 & 333.30 & 2.65 & 12.80 & 0.975 & 0.0030 \\
344 & 342.30 & 3.22 & 12.80 & 1.169 & 0.0029 \\
354 & 352.03 & 3.63 & 12.80 & 1.289 & 0.0028 \\
364 & 362.50 & 3.86 & 12.80 & 1.351 & 0.0027 \\
\hline
\end{tabular}

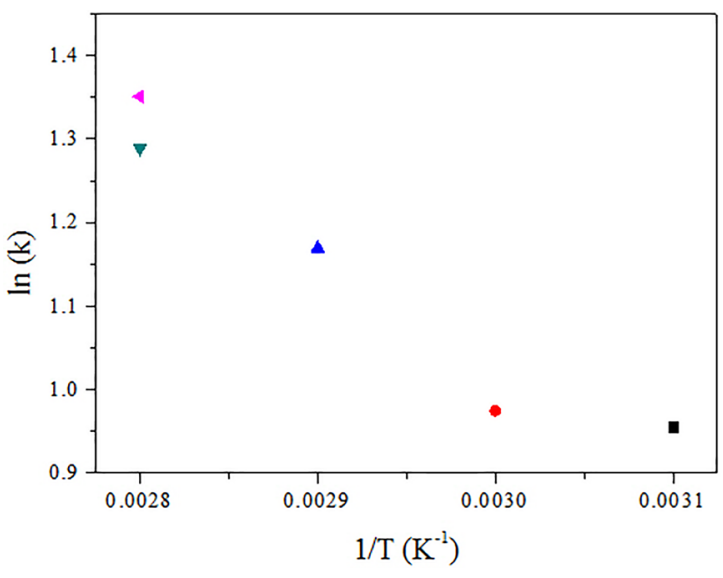

Figure 8. Graph of $\ln (\mathrm{k})$ as a function of $1 / \mathrm{T}$. $-324 \mathrm{~K}$; $\bullet-334$ $\mathrm{K} ; \boldsymbol{\Delta}-344 \mathrm{~K} ; \boldsymbol{\nabla}-354 \mathrm{~K} ; 4-364 \mathrm{~K}$

A continuous mass loss of 373 to $673 \mathrm{~K}$ is observed, characteristic of silicates dehydration. Whenever slag's hydration and aging process occurs, silicates that are organized in crystalline structure such as larnite, for example (observed by X-ray diffraction), capture the water in its structure with a specific binding energy. This can be seen in the peaks formed at the temperature of $533 \mathrm{~K}$ and $623 \mathrm{~K}$.

The carbonate is formed in the samples after $\mathrm{CO}_{2}$ capture from the atmosphere when they are subjected to a long process of exposure to the atmosphere. It is possible to observe that at a temperature of approximately $973 \mathrm{~K}$ there is a peak in the DTA curve which is associated with the decomposition of the carbonate (formed during exposure of the sample to the air) releasing $\mathrm{CO}_{2}$.

It is observed in the range of 293 to $1173 \mathrm{~K}$ the sample mass loss was $2.83 \%$, this result is very close to the result found by Machado ${ }^{10}$, whose value is characteristic of magnesium oxide $\left(\mathrm{Mg}(\mathrm{OH})_{2}\right)$, calcium hydroxide $\left(\mathrm{Ca}(\mathrm{OH})_{2}\right)$ and calcium and magnesium carbonates $\left(\mathrm{CaCO}_{3}\right.$ or $\left.\mathrm{MgCO}_{3}\right)$, indicating that the loss of mass is due to dehydration and decarbonation of these compounds.

Figure 4 shows the thermogram of the same sample (lot 02), with an oxidizing atmosphere (synthetic air), after the test of removal of water $\left(\mathrm{H}_{2} \mathrm{O}\right)$ and carbon dioxide $\left(\mathrm{CO}_{2}\right)$ in an inert atmosphere. This second stage was established to evaluate the oxidation of $\mathrm{Fe}^{0}$ and $\mathrm{FeO}$, obtaining additional information on the presence of oxidizable iron. Therefore, the mass gain recorded in the TGA curve comes from the
Table 3. Parameters adjusted for equation 2 that relates the expandability with time

\begin{tabular}{lccc}
\hline $\begin{array}{c}\text { Temperature } \\
(\mathrm{K})\end{array}$ & $\mathrm{a}$ & $\mathrm{b}$ & $\mathrm{c}$ \\
\hline 324 & 2.439 & 2.357 & 0.690 \\
334 & 2.547 & 2.436 & 0.685 \\
344 & 3.041 & 2.991 & 0.579 \\
354 & 3.440 & 3.403 & 0.521 \\
364 & 3.698 & 3.679 & 0.330 \\
\hline
\end{tabular}

increase of oxygen incorporated to $\mathrm{Fe}^{0}$ and $\mathrm{FeO}$ to form the most oxidized form of iron, $\mathrm{Fe}_{2} \mathrm{O}_{3}$ (hematite).

\subsubsection{Chemical analysis}

\subsubsection{Ethylene glycol}

A content of $5 \%$ of free calcium oxide was obtained in the slag of lot 01 , this value being close to that determined by Machado ${ }^{10}$ of $4.7 \%$. With this result, we can then consider that this slag is not cured.

\subsubsection{Fluorescence of $X$-rays}

The results of the quantitative chemical analyzes carried out in lot 02 are presented in Table 1. It is noted that there is a high content of calcium oxide (which is explained by the process with which this slag is generated) and iron oxide equivalent (wüstita). From these results a the high density value, and ethylene glycol test reflect the high amount of iron oxides.

\subsection{Microstructural characterization}

\subsubsection{X-ray diffraction (XRD)}

The main crystalline compounds identified in the slag were portlandite $\left(\mathrm{Ca}(\mathrm{OH})_{2}\right)$, wüstita $(\mathrm{FeO})$, larnite $(2 \mathrm{CaO}$. $\left.\mathrm{SiO}_{4}\right)$, calcium oxide $(\mathrm{CaO})$, calcium carbonate $\left(\mathrm{CaCO}_{3}\right)$ and carbon (C). In Fig. 5 it is possible to observe the overlapping of the difratograms of lot 02 and 03 for better visualization of the present phases.

The basic difference of the two lots is found only in the variation of the granulometry of the material. Note that the material with the highest particle size (lot 03) shows portlandite $\left(\mathrm{Ca}(\mathrm{OH})_{2}\right)$ and carbon peaks much larger than the material with the smallest particle size (lot 02 ). This fact can be justified by the 
way in which the grains at the time of grinding were fragmented, where $\mathrm{Ca}(\mathrm{OH})_{2}$ particles war obtained with a size of less than $20 \mathrm{~nm}$ do not appear in XRD. Besides that, possibly, the sample of greater granulometry may have hydrated more easily and concentrated grains with higher contents of these compounds.

A high iron oxide $(\mathrm{FeO})$ value is also observed in both samples, where the batch 02 sample has the highest content $(20.32 \%)$. This is justified by the fact that the sample is thinner and can suffer corrosion more easily. In spite of this, the contents found for both iron and other elements are in agreement with those determined by Machado ${ }^{10}$ in their characterization.

\subsubsection{Optical Microscopy}

Figures 6 (a) to 6 (d) show photomicrographs of the lot 03 sample observed by optical microscopy and subjected to different magnifications (50 to 1000x). A variety of morphologies are present in the particles that are possibly produced by differences in the chemical composition and thermal history of the material. Some grains have more than one phase, this is observed due to the heterogeneity of colors in the same grain.

In Figure 6(a) it can be observed that there are blue points, supposedly corresponding to the Larnita $\left(\mathrm{C}_{2} \mathrm{~S}\right)$. The fact that the sample was polished in water may have caused this compound to react to a bluish color.

In Figure 6(b), which is the same micrograph of Figure 6(a), but with polarized light, one can identify a bright rectangular compound that probably corresponds to alita $\left(\mathrm{C}_{3} \mathrm{~S}\right)$.

In Figure 6(c) a rounded particle is observed, with white coloration and contoured by crystallized particles. This particle is possibly a metal, iron, and the crystallized particles that surround it probably corresponds to its oxide, $\mathrm{FeO}$.

Figure 6(d) shows a longer, gold-colored particle. This particle has characteristics of graphite, visualized when there is incidence of light at different angles.

In the photomicrographs it was possible to observe the size of the phases and the structure of pores that will be responsible for the fragmentation pattern of the material during the hydration and aging process. However, in this research the compounds identified are only suggestions, and it is necessary to use complementary techniques to identify such compounds and suggested phases.

\subsection{Expansibility of SS}

\subsubsection{Evaluation of the expandability}

During the evaluation of the expansive potential of SS with different temperatures, four replicates were performed daily for the samples. Bearing the averages it was possible to calculate the expansion for each mini-proctor according to the volumetric expansion equation (equation 1), previously presented.
The assays were performed for each one at the four miniproctors, for calculation purposes, the expansions means of each assay were calculated and presented in Figure 7.

According to Figure 7 it is possible to observe that the expansion occurs as a logarithmic curve and its value increases with test temperatures. It's also noted that the tests with a temperature of $324 \mathrm{~K}$ and $334 \mathrm{~K}$ obtained very close results, possibly this error may be linked to an error in the temperature of the test, or that the hydration of some of the oxides did not reach the activation condition.

\subsection{Estimation of kinetic parameters}

The activation energy and the pre-exponential factor of the Arrehnius equation were estimated from the maximum expansion (k) obtained for the various temperatures. Table 2 presents the data used for the estimation of kinetic parameters. And Figure 8 presents the result obtained from $\ln (\mathrm{k})$ as a function of the inverse of the temperature.

The straight line fitted to the data set of Figure 8 has an adjustment coefficient of 0.9457 , obtaining as an equation $\ln (\mathrm{k})=5,5623-1506,7 \cdot\left(\frac{1}{T}\right)$.The activation energy calculated from this equation is $12.5 \mathrm{KJ} \mathrm{mol}^{-1}$. Replacing the value of the activation energy $\left(E_{a}\right)$ in the Arrehnius equation, we obtain the value of the pre-exponential factor, $260.42 \%$.

It is observed that the points referring to the expected temperatures of $61^{\circ} \mathrm{C}$ and $51{ }^{\circ} \mathrm{C}$ are somewhat distant from linearization and are therefore responsible for the value of the correlation coefficient. This divergence may refer to errors in the measured water temperature.

With the values of activation energy and the preexponential factor determined, it is possible to estimate the maximum expansion $(\ln (\mathrm{k}))$ at various temperatures. It is worth mentioning that the estimation performed in this research is appropriate for the determined time of 12.8 days and for samples with characteristics that fit the specifications of lot 03 , mainly with respect to granulometry.

\subsection{Data processing}

To better understand what happens during the expansion experiment, we tried to model the expansion curve mathematically.

An exponential asymptotic function was adopted because it seems to express well the idea of initially having a large expansion velocity, which tends to zero in very long times when the material has already stabilized. This function can be expressed by equation 3 .

$$
\operatorname{Exp}=a-b . c^{t}
$$

Where $\operatorname{Exp}$ is the expansion (\%), $t$ is the time (days) and $a, b$ and $c$ are the adjustment parameters, where $\mathrm{c}$ is always less than 1. Due to this fact, when time tends to infinity, second term draw nears to zero, inducing the expansion closer to $a$, respectively potential for expandability. 
By the norm DNIT $113^{14}$ the experiment time is fixed in 14 days. If the experiment were extended indefinitely the expansion would tend asymptotically to the value of $a$. Wherefore it will always be a little higher than the potential estimated. When the experiment time is zero $\left(c^{t}=1\right)$ the $b$ value will be close to $a$ value. Since the expansion curve has to necessarily start from zero, which is at time zero, the expandability must be equal to zero.

The parameter $c$ represents the function curvature measure. How much smaller the $c$ greater the curvature. When $c$ tends to 1 , equation 3 tends to be linear at initial times and achieves the asymptote in very long times.

The parameters $a, b$ and $c$ are adjustment in fact a function of the temperature, because during the work, it could be observed that the expansion is directly related to the potential provided for the reaction to occur. Table 3 presents these adjustment parameters, estimated for the temperatures worked during the research.

In accordance with this information, it is believed that the slag will have a better acceptance, expansion and appreciation in the market, since the operator can predict the maximum expansion in the particular temperature and granulometry specific conditions for its volumetric stabilization and thus to overcome time and expansion indetermination problem. In addition, it will be possible to develop procedures to accelerate the curing of the slag and to guarantee the quality of the volumetric stability.

\section{Conclusions}

The characterization of SS proved the presence of expansion compounds ( $\mathrm{CaO}$ and $\mathrm{MgO})$. Through the static adapted measure it was possible to verify its dependence with temperature by means of Arrhenius equation.

This modeling resulted in an equation whose expansion can be described like a time function.

Finally, it is emphasized that proposed kinetic parameters estimation are restricted to SS with the granulometry and characteristics established in this research, it was necessary to correlate and extend these criteria to cover all types of slag and granulometry.

\section{Acknowledgments}

The steel industry for the supply of material and infrastructure and Unileste for the infrastructure for the development of this study.

\section{References}

1. Das B, Prakash S, Reddy PSR, Misra VN. An overview of utilization of slag and sludge from steel industries. Resources, Conservation and Recycling. 2007;50(1):40-57. DOI: 10.1016/j. resconrec.2006.05.008
2. Costa KA, Guimarães ACR, Reis MM, Santana CSA. Study of controlled leaching process of steel slag in soxhlet extractor aiming employment in pavements. Matéria (Rio de Janeiro). 2017;22(2):e11823. DOI: 10.1590/s1517-707620170002.0155

3. Busnello EC. Avaliação do potencial de expansão da escória de aciaria estabilizada para utilização em sub-base e base de pisos industriais de concreto. In: $58^{\circ}$ Congresso Brasileiro do Concreto; 2016 Oct 11-14; Belo Horizonte, MG, Brazil. p. $1-15$.

4. Souza Junior DS. Estudo do comportamento de escórias de alto-forno a carvão vegetal produzidas a partir de ativação a quente. [Dissertation]. Belo Horizonte: Federal University of Minas Gerais; 2007

5. Sofilic T, Mladenovic A, Sofilic U. Defining of EAF steel slag application possibilities in asphalt mixture production. Journal of Environmental Engineering and Landscape Management. 2011;19(2):148-157. DOI: 10.3846/16486897.2011.580910

6. Arrivabene LF, Pinto Junior LAB, Oliveira JR, Tenório JAS, Espinosa DCR. Viabilidade técnica da fabricação de cimento com mistura de escória de aciaria LD e resíduo de granito. REM: Revista Escola de Minas. 2012;65(2):241-246. DOI: 10.1590/S0370-44672012000200013

7. Ulubeyli GC, Artir R. Sustainability for Blast Furnace Slag: Use of Some Construction Wastes. Procedia - Social and Behavioral Sciences. 2015;195:2191-2198. DOI: 10.1016/j. sbspro.2015.06.297

8. Gao X, Okubo M, Maruoka N, Shibata H, Ito T, Kitamura SY. Production and utilisation of iron and steelmaking slag in Japan and the application of steelmaking slag for the recovery of paddy fields damaged by Tsunami. Mineral Processing and Extractive Metallurgy. 2014;124(2):116-124. DOI: 10.1179/1743285514y.0000000068

9. Geyer RMT. Estudo sobre a potencialidade de uso das escórias de aciaria como adição ao concreto. [Thesis]. Porto Alegre: Federal University of Rio Grande do Sul; 2001.

10. Machado AT. Estudo comparativo dos métodos de ensaio para avaliação da expansibilidade das escórias de aciaria. [Thesis]. São Paulo: University of São Paulo; 2000.

11. Raposo COL. Estudo experimental de compactação e expansão de uma escória de aciaria LD para uso em pavimentação. [Dissertation]. Vitória: Federal University of Espírito Santo; 2005.

12. Barbosa MCR, Justulim D, Machado IS, Machado AR. Avaliação do fenômeno físico-químico relacionado a expansibilidade da escória de aciaria para uso em pavimentação. In: $45^{a}$ Reunião Anual de Pavimentação; 2016 Sep 20-23; Brasília, DF, Brazil.

13. Pena DC. Avaliação da Expansibilidade da Escória de Aciaria LD curada a vapor para Utilização em peças de Concreto para Pavimentação. [Dissertation]. Vitória: Federal University of Espírito Santo; 2004.

14. Brazil. National Department of Transport Infrastructure (DNIT). Pavimentação Rodoviária - Agregado Artificial - Avaliação do Potencial de Expansão de Escória de Aciaria - Método De Ensaio. In: Norma DNIT 113; Brasília: DNIT; 2009. p. 1-12. 
15. United States. Department of Transportation. Evaluation of Potential Expansion of Steel Slags. In: PTM 130; Pennsylvania: Department of Transportation; 2016. p. 1-8.

16. Brazilian Association of Technical Standards (ABNT). NBR NM 13 - Cimento Portland - Análise química - Determinação de óxido de cálcio livre pelo etileno glicol. Rio de Janeiro: ABNT; 2004. p. 1-10.

17. Mehta PK, Monteiro PJ. Concrete: Microstructure, Properties, and Materials. New York: McGraw-Hill; 2013.

18. Verapathran M, Murti P. High performance concrete with steel slag aggregate. Gradevinar. 2014; 66(7):605-612. DOI: 10.14256/jce.1052.2014
19. Rohde L. Escória de aciaria elétrica em camadas granulares de pavimentos - estudo laboratorial. [Dissertation]. Porto Alegre: Federal University of Rio Grande do Sul; 2002.

20. Garcia E. Approche expérimentale et corrélations dans les systèmes complexes: Modes de broyage et réactivités du ciment alumineux Fondu. [Thesis]. Montpellier: University of Montpellier; 1999.

21. Gregg SJ, Sing KSW. Adsorption, Surface Area and Porosity. London: Academic Press; 1982. 